\title{
Estimation of DNA Content in Uveal Melanomas by Flow Cytometry
}

\author{
I. G. RENNIE ${ }^{1}$, R. C. REES ${ }^{3}$, M. A. PARSONS ${ }^{2}$, J. LAWRY ${ }^{3}$, D. COTTAM ${ }^{1,3}$ \\ Sheffield
}

\begin{abstract}
Summary
Flow cytometry was used to evaluate ploidy and tumour cycle kinetics in fresh tissue samples obtained from 19 uveal melanomas. The results were compared with other parameters including, histological cell type, tumour size and anatomical location.

Three tumours $(\mathbf{1 5 . 8 \%})$ ) were aneuploid (two mixed cell, one epithelioid cell). Cell turnover was estimated in the 16 diploid tumours by summating the total percentage of cells in $\mathrm{S}$ and $\mathrm{G} 2 / \mathrm{M}$ phases. We found the mean percentage of cells in $\mathrm{G} 2 / \mathrm{M} / \mathrm{S}$ to be $5.96 \%$ (range $2.2-9.8 \%$ ). Spindle cell neoplasms appeared to have lower cell turnover rates $(4.5 \pm 1.2 \%)$ than epithelioid cell turnover $(8.4 \pm 1.2 \%)$. There was no correlation between cell turnover and either tumour size or anatomical location.
\end{abstract}

Uveal melanomas (ciliary body and choroid), although uncommon in the context of general neoplasia, are the most common primary adult intraocular malignancy, they frequently metastasize, and approximately half of the patients die from their disease within 15 years of enucleation. ${ }^{1}$ The introduction of new treatment modalities over the past few decades has not reduced substantially the mortality inflicted by these tumours. Although the overall ability of uveal melanomas to produce metastases is high, it is well recognised that metastatic potential varies from tumour to tumour, some having little or no metastatic potential, whereas others readily metastasize, and, in part, these differences are reflected by the histological appearances of the tumour. ${ }^{2}$ In addition to the metastatic potential, the relative growth rates of the primary tumours may also vary. ${ }^{3,4}$

Flow cytometry enables the rapid analysis of single cell suspensions by virtue of the light scatter properties of cells, which may or may not be stained with DNA or protein specific fluorochromes. It has been shown to be a reliable quantitative method of determining the DNA content of a tumour cell sample. ${ }^{5}$ From this, details of the cell kinetics, the percentage of cells undergoing division (those cells in G2 $M$ and S phase of the cell cycle relative to those in $\mathrm{G} 0 / \mathrm{G} 1$ ), and ploidy (total DNA content) of the tumour cell population can be obtained. The presence of non-diploid (aneuploid) cells in some human tumours may infer a poor prognosis. ${ }^{5}$ To date, flow cytometric studies of uveal melanomas have been limited to analysis of histological material recovered from paraffin embedded specimens ${ }^{6,7}$ Following the method of Hedley et al. (1983), ${ }^{8}$ Meechan and Char $^{7}$ retrospectively correlated ploidy and clinical outcome, and found that hyperploidy correlated with

From Departments of Ophthalmology ${ }^{1}$, Pathology² and Virology ${ }^{3}$, University of Sheffield Medical School, Royal Hallamshire Hospital, Glossop Road, Sheffield S10 2JF.

Correspondence to: I. G. Rennie, Department of Ophthalmology, Floor 'O', Royal Hallamshire Hospital, Glossop Road, Sheffield S10 2JF, England. 
poor prognosis. Due to the reported technical difficulties encountered when using paraffinembedded material for DNA flow cytometry, ${ }^{9}$ namely possible formal saline fixation induced artefacts, including reduced fluorescent intensity and high levels of cellular debris which make histogram interpretation difficult, ${ }^{7}$ we have used flow cytometry in a prospective study to determine the cellular DNA content in fresh tumour tissue obtained from 19 uveal melanomas. In addition to providing a ploidy value for the tumour tissue, this technique permits us to obtain an index of cell proliferation by studying the percentage of cells in each phase of the cell cycle. The results and their relationship to various cycle tumour parameters including, anatomical location, tumour size and histological cell type are discussed.

\section{Patients and Methods}

\section{Tumour Biopsy Tissue and Patients}

Nineteen patients referred to our unit with a diagnosis of uveal melanoma were included in this study. All patients were subject to a full clinical assessment, which included, in most cases, a full general examination, chest X-ray, liver function tests, liver ultrasonography and abdominal computerised tomography in an attempt to exclude overt metastatic disease. None of the patients had demonstrable metastatic disease at presentation, and they were managed by enucleation (18 patients) or local tumour resection (patient 17). Tumour size was estimated in some patients using digital B scan ultrasonography (Cooper-Vision) in addition to direct measurement of the pathological specimen in all patients (see below).

\section{Tissue Preparation}

Immediately after enucleation, the globe was opened along an axis parallel to the longest diameter of the tumour. Any overlying retina was removed to expose the tumour surface, and samples were taken for flow cytometry. The globe containing the residual tumour was fixed in buffered $3 \%$ glutaraldehyde solution and processed into plastic polymer/paraffin wax for routine histological examination. Tumours were classified according to the New AFIP Classification of Melanocytic Tumours of the Uvea. ${ }^{10}$ Tumour size was estimated in all patients using a graticule in conjunction with a $\times 1$ microscope objective. Based on the combination of these results, and the ultrasound estimation of tumour size, the tumours were classified as small, medium or large according to Shields. ${ }^{11}$ The degree of pigmentation was assessed using an arbitrary scale $(0-3)$.

\section{Flow Cytometry}

Tumour samples for flow cytometry were placed in RPMI transport medium (Biological Industries, Scotland) supplemented with $10 \%$ fetal bovine serum (Gibco Limited, Scotland). Following a modified method of Engleholm et al., ${ }^{12}$ the tumour samples were cut into $1 \mathrm{~mm}$ cubes with scalpel blades and digested with $0.025 \%$ type 2 collagenase with the additional inclusion of $0.05 \%$ pronase $\mathrm{E}$, and $0.5 \mu \mathrm{M}$ dithiothreitol (all from Sigma Chemical Co Ltd, UK) in phosphate buffered saline (which was found to aid tumour dissociation and minimise cell clumping due to any mucin present within the sample) and rotated at $37^{\circ} \mathrm{C}$ for two hours. The cell suspension was washed twice with RPMI supplemented with $10 \%$ fetal bovine serum, centrifuged at $390 \mathrm{~g}$ for ten minutes, and held on ice at $4^{\circ} \mathrm{C}$.

Cell suspensions were filtered through a $50 \mu \mathrm{m}$ mesh to remove cell clumps prior to DNA staining with the intercallating fluorochrome, propidium iodide (PI) (Sigma Chemical Co Ltd, UK), as reviewed by Taylor and Milthorpe. ${ }^{13}$ However, in the present study reagent concentrations were reduced to $0.2 \%$ triton $\times-100(100 \mu \mathrm{l}$ per 106 pelleted cells) in buffered saline (added to permeabilise cell membranes); and $20 \mu \mathrm{g} / \mathrm{ml}$ PI (400 $\mu \mathrm{l}$ in PBS) with staining for 15 minutes at room temperature. ${ }^{13}$

Cell suspensions were analysed using a FACS 420 flow cytometer with an accessory Consort 30 computer (Beckton Dickinson [UK] Ltd) using a $488 \mathrm{~nm}$ excitation laser wavelength, and measuring the emission fluorescence of PI through a $530 \mathrm{~nm}$ band pass filter. A minimum of 10,000 cells were analysed for each sample. The intensity of the fluorescence was considered proportional to their DNA content. Cell cycle measurements were made using the planimetric method of 
Chrisman et al. ${ }^{14}$ and Dean ${ }^{15}$ assuming that G0/G1, S, G2/M phase cells adopt binomial distributions. The ploidy of the sample was calculated, with normal human lymphocytes forming the diploid standard, using the equation:

$$
\text { ploidy index }=
$$

G0/G1 peak channel (tumour cells)

G0/G1 peak channel (normal cells)

Diploid cells therefore have an index of one and tetraploid cells an index of two in accordance with the convention on nomenclature for DNA cytometry. ${ }^{16}$ The quality of the sample was assessed by the coefficient of variation $(\mathrm{CV})$ of the $\mathrm{G} 0 / \mathrm{G} 1$ peak.

\section{Statistical Analysis}

The Mann-Whitney U-test was used to assess statistical significance, and results are expressed as the mean value \pm the standard deviation.

\section{Results}

Patients

Of the 19 patients, there were 13 females
$(68.4 \%)$ and 6 males $(32.6 \%)$ with a mean age of 64.3 years (range $10-80$ years). The mean period of follow up was 14.8 months (range 1-35 months). During this time three patients died. Patient 3 died 24 months after enucleation from proven metastatic disease (liver biopsy). Patient 4 died 10 months after enucleation from suspected metastatic disease. Patient 11 died 15 months after enucleation, but unfortunately details relating to this patient's death were not available. All the remaining patients are alive and without evidence of overt metastatic disease. These data are summarised in Table I.

\section{Histological examination}

Thirteen patients had choroidal melanomas $(68.4 \%)$; of these, seven had one tumour edge located anterior to the equator. Six patients $(31.4 \%)$ had ciliary body tumours. Fifteen tumours were classified as large $(79 \%)$, and the remainder were medium sized $(21 \%)$.

Two tumours were classified as spindle (10.5\%), 13 as mixed (68.4\%) and four as epithelioid cell $(21 \%)$ (Table I). Fourteen $(73.7 \%)$ were lightly pigmented (grades $0-1$ ) and five $(26.3 \%)$ were heavily pigmented

Table I Personal data, including present status

\begin{tabular}{|c|c|c|c|c|c|c|}
\hline \multicolumn{3}{|c|}{ Patient } & \multicolumn{4}{|c|}{ Tumour } \\
\hline No. & Sex & Age (yrs) & Status & Location & Size & Cell type \\
\hline 01 & $\mathrm{~F}$ & 79 & Alive & Choroid & Large & Spindle \\
\hline 02 & $\mathbf{M}$ & 70 & Alive & Choroid & Large & Epithelioid \\
\hline 03 & $\mathrm{~F}$ & 55 & Deceased ${ }^{1}$ & Ciliary body & Large & Mixed \\
\hline 04 & $\mathrm{~F}$ & 76 & Deceased $^{2}$ & Choroid & Large & Mixed \\
\hline 05 & $\mathrm{~F}$ & 65 & Alive & Ciliary body & Large & Mixed \\
\hline 06 & $\mathbf{F}$ & 62 & Alive & Choroid & Large & Mixed \\
\hline 07 & $\mathrm{~F}$ & 79 & Alive & Ciliary body & Medium & Mixed \\
\hline 08 & $\mathbf{M}$ & 66 & Alive & Choroid & Large & Mixed \\
\hline 09 & $\mathrm{~F}$ & 71 & Alive & Ciliary body & Large & Mixed \\
\hline 10 & $F$ & 67 & Alive & Choroid & Large & Epithelioid \\
\hline 11 & M & 79 & Deceased $^{3}$ & Ciliary body & Large & Mixed \\
\hline 12 & $\mathbf{F}$ & 54 & Alive & Choroid & Medium & Mixed \\
\hline 13 & $\mathrm{~F}$ & 47 & Alive & Choroid & Medium & Epithelioid \\
\hline 14 & $\mathbf{M}$ & 83 & Alive & Choroid & Large & Epithelioid \\
\hline 15 & M & 40 & Alive & Choroid & Medium & Mixed \\
\hline 16 & $\mathrm{~F}$ & 40 & Alive & Choroid & Large & Mixed \\
\hline 17 & M & 52 & Alive & Choroid & Large & Spindle \\
\hline 18 & $\mathrm{~F}$ & 69 & Alive & Ciliary body & Large & Mixed \\
\hline 19 & $\mathrm{~F}$ & 69 & Alive & Choroid & Large & Mixed \\
\hline
\end{tabular}

${ }^{1}$ Proven metastatic disease.

2 Presumed metastatic disease.

${ }^{3}$ No details availalble. 
(grades 2-3). A significant inflammatory infiltrate was not observed in any of the tumours studied.

\section{Flow Cytometic Analyses}

Of the 19 tumours analysed, $16(84.4 \%)$ were diploid and three $(15.8 \%)$ were aneuploid. The three aneuploid tumours had distinct and differing histograms: patient 4 had a diploid and tetraploid tumour, patient 6 a diploid and aneuploid tumour and patient 14 a pure aneuploid tumour (Fig. 1).

The percentages of cells in $\mathrm{G} 2 / \mathrm{M}$ and $\mathrm{S}$ phases in the 16 diploid specimens were summated to provide an index of cell proliferation. The percentage of cells in $\mathrm{G} 2 / \mathrm{M} / \mathrm{S}$ was $5.96 \pm 2.13 \%$ (range 2.2 to $9.8 \%$ ).

The flow cytometry results were then compared with histological cell type. Of the 16 diploid tumours, there were two spindle, eleven mixed and three epithelioid cell tumours. The proportion of cells in $\mathrm{G} 2 / \mathrm{M} / \mathrm{S}$ was $4.5 \pm 1.2 \%$ for spindle cell, $5.5 \pm 2.0 \%$ for mixed cell and $8.4 \pm 1.2 \%$ for epithelioid cell tumours (Table II). Of the three aneuploid tumours, two were mixed and one was epithelioid cell.

There was no significant difference in the percentage of cells in $\mathrm{G} 2 / \mathrm{M} / \mathrm{S}$ between the medium $(6.0 \pm 3.0 \%)$ and large $(5.94 \pm 2.0 \%)$ tumours. When the relationship between location within the eye and cell proliferation was examined, tumours involving the ciliary body had a lower percentage of cells in G2/M/S (4.9 $\pm 2.06 \%)$ than choroidal neoplasms $(6.59 \pm 2.0 \%)$, but this was not statistically significant.

It was noted that the mean coefficient of variation $(\mathrm{CV})$ of the $\mathrm{G} 0 / \mathrm{G} 1$ peaks, which is an index of sample quality, was quite high (mean 8.19, range 5.2-13). In view of this the relationship between the degree of pigmentation and coefficient of variation was examined. When tumours with light pigmentation (grades 0-1) were compared with those which were heavily pigmented (grades 2-3) a significant difference was noted between the coefficient of variation of the groups (lightly pigmented group $7.44 \pm 1.4$, heavily pigmented group $10.80 \pm 1.7, P=0.014)$. This suggests that heavy cellular pigmentation may interfere with either the absorption of the
DNA fluorochrome into the cell nucleus or the emission characteristics of the cell during flow cytometric analysis. Control (peripheral blood lymphocyte) samples run in parallel to each tumour sample had low CV values $(6.70 \pm 0.9)$ suggesting that staining and flow cytometric techniques were not responsible for the high values.

\section{Discussion}

Aneuploidy is a recognised feature of the many human tumours. ${ }^{17}$ There is increasing evidence to suggest that ploidy may reflect the biological behaviour of a tumour, and that aneuploidy may correlate with poor prognosis. ${ }^{5}$ Aneuploidy has been reported to be present in $70-89 \%$ of cutaneous malignant melanomas. ${ }^{17-19}$ Sondergaard et al. ${ }^{19}$ found that, whilst aneuploidy was not an absolute criterion for malignancy in cutaneous melanomas, it appeared to correlate with a poor prognosis.

Investigation of the DNA content in uveal melanomas by flow cytometry is limited.,7 Meecham and $\mathrm{Char}^{6}$ studied the DNA content of paraffin embedded tumour samples from 79 patients with uveal melanoma; of these 64 had interpretable DNA histograms. Aneuploidy was found in $36 \%$ of the specimens. When these results were compared retrospectively with patient survival it was found the hyperploidy correlated with poor prognosis. In contrast, Shapiro et al., ${ }^{7}$ in a retrospective study of 36 uveal melanomas, found the incidence of aneuploidy to be $77 \%$; in this study the authors were unable to detect any association between a high DNA (ploidy) index and death from metastatic disease. In the present study we have demonstrated aneuploidy in three out of 19 tumours examined $(15.8 \%)$. This figure is lower than that found in either of the previous studies and may, at least in part, be a reflection of our relatively small sample size. The presence of aneuploidy appears to correlate well with reduced survival, but it is obviously not a prerequisite. Despite the short follow-up period of this study (mean 14.8 months), two patients with pure diploid cell profiles have died, one of them from proven metastatic disease. Meecham and Char ${ }^{6}$ reported 14 deaths out of 41 patients $(34 \%)$ with pure diploid tumours. ${ }^{6}$ 
PATIENT NO. 1

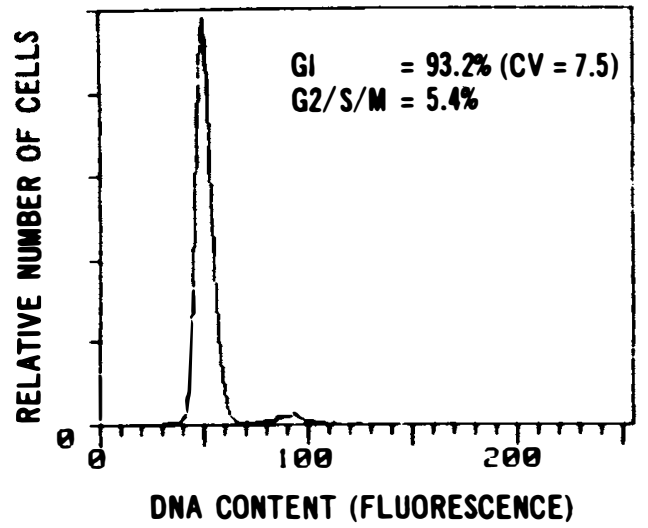

PATIENT NO. 6

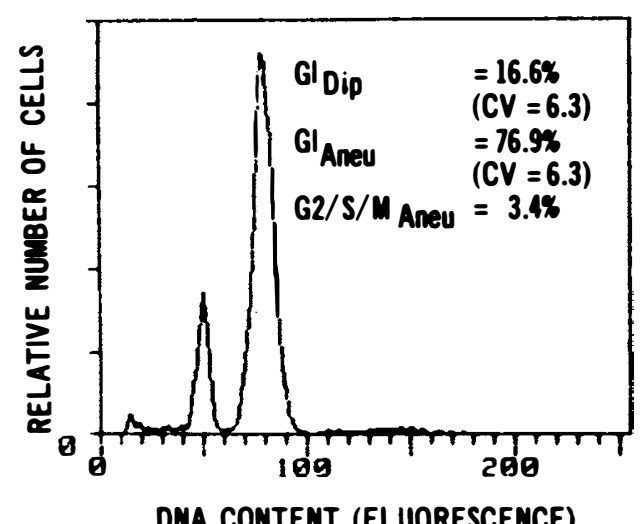

PATIENT N0.4

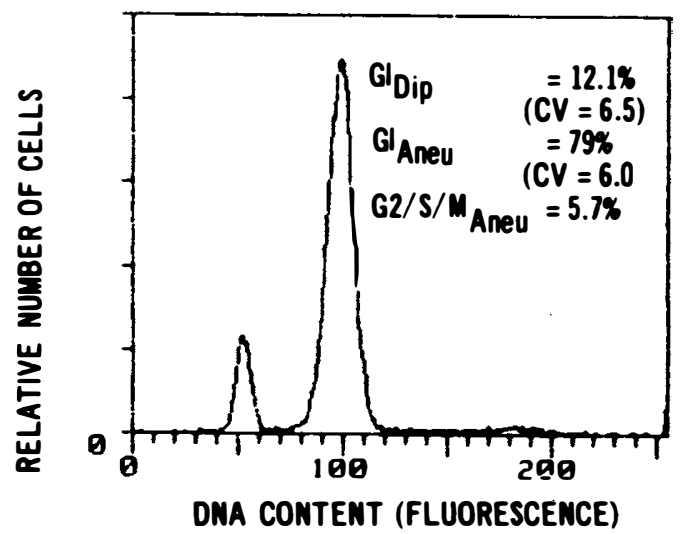

PATIENT NO. 14

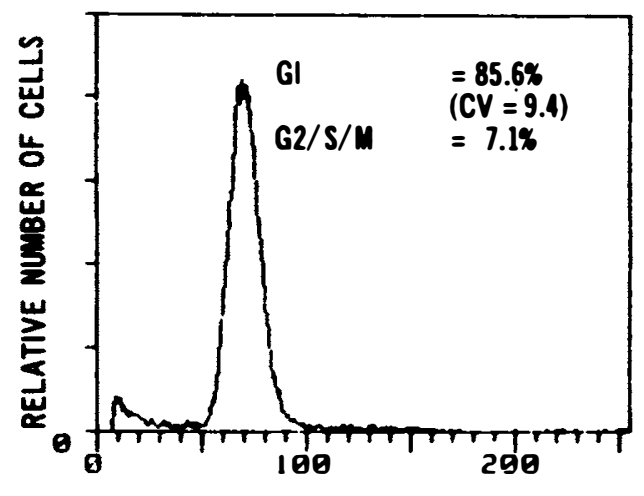

DNA CONTENT (FLUORESCENCE)
Fig. 1

Flow cytometry histogram. Top left: Patient No 1 Top right: $\quad$ Patient No 4 Middle left: Patient No 6 Middle right: Patient No 14 Bottom:

CONTROL PBL

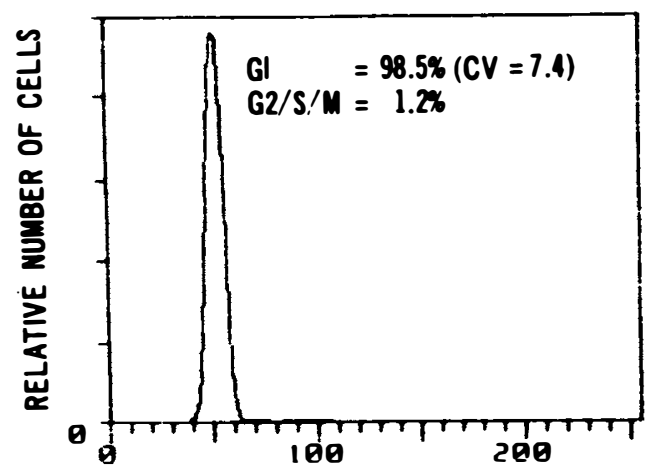

DNA CONTENT (FLUORESCENCE)

A normal diploid profile showing a single G1/G0 peak.

$A$ non overlapping diploid (first peak) and tetraploid (second peak) pattern.

A non overlapping diploid (first peak) and hyperploid (second peak) pattern.

A pure aneuploid (hyperploid) pattern.

Peripheral blood lymphocyte control. A normal diploid pattern. 
Table II Comparison of cell type with respect to mean percentage cells in $62 / \mathrm{M} / \mathrm{S}$

\begin{tabular}{lrcccc}
\hline Cell type & $N$ & Mean & Std. dev. & Minimum & Maximum \\
\hline Spindle cell & 2 & 4.5 & \pm 1.2 & 3.6 & 5.4 \\
Mixed cell & 11 & 5.5 & \pm 2.0 & 2.2 & 9.1 \\
Epithelioid cell & 3 & 8.4 & \pm 1.2 & 7.6 & 9.8 \\
\hline
\end{tabular}

In view of this, we examined the rate of cell turnover within the diploid group by comparing the total number of cells counted in $\mathrm{G} 2 / \mathrm{M}$ and $\mathrm{S}$ phases. Although this value may reflect the relative activity of a tumour, it must be interpreted with caution. We have assumed that within the sample the only cells actively dividing are tumour cells. It is possible that other cells, for example those which constitute the fibrovascular stroma of the tumour, are undergoing division and account for a percentage of cells in S and G2/M phases. However, as fibrovascular activity is probably directly related to tumour growth, this is unlikely significantly to influence the results. One further assumption is that the cells present in G0/G1 are all tumour cells. This is almost certainly incorrect, for it is recognised that inflammatory cells may constitute a proportion of the total mass of uveal melanomas. ${ }^{18} \mathrm{~A}$ notable inflammatory infiltrate was not observed in any of the tumours studied and it is therefore unlikely that this factor caused a significant error.

We found that the percentage of cells in $\mathrm{G} 2 / \mathrm{M} / \mathrm{S}$ to range between $2.2 \%$ to $9.8 \%$ $(5.96 \pm 2.13 \%)$. These figures conflict with those obtained from studying paraffin embedded tissue where the mean number of cells in G2/M/S was found to be $30 \% .{ }^{7}$ The difference, at least in part, may reflect the difficulties in interpreting histograms obtained from paraffin mixed material. When the percentage of cells in $\mathrm{G} 2 / \mathrm{M} / \mathrm{S}$ was correlated with histological cell type, there was a tendency for spindle cell tumours to have lower cell turnover $(4.5 \pm 1.2 \%)$ than epithelioid cell tumours $(8.4 \pm 1.2 \%)$. Mixed cell tumours were, not unexpectedly, distributed more evenly across the range of values $(5.5 \pm 2.0 \%)$. These findings are in agreement with those of Augsberger et al. ${ }^{3}$ who observed that spindle cell neoplasms tended to have longer doubling time than tumours containing epithelioid cells. There appeared no difference in rates of cell turnover between the medium $(6.0 \pm 3.0 \%)$ and large $(5.94 \pm 2.0 \%)$ tumour groups. We appreciate that whilst these values reflect cell turnover at the time of enucleation, and that it is probable that tumour growth is not uniform with tumours undergoing periods of relative quiescence and increased activity. Indeed, Char et al. suggest that choroidal melanomas frequently grow rapidly over a period of relative inactivity. ${ }^{21}$

The relatively small numbers of tumours in our study dictates that the results must be viewed with caution. Furthermore, we appreciate that our sample is biased in containing only large and medium sized tumours, which reflects the changing pattern of management of the small and medium-sized tumours. This short follow-up period precludes any attempt to correlate the survival with ploidy and cell cycle analysis. Nevertheless, we believe that flow cytometric analysis of ocular melanomas has the potential for increasing the accuracy with which we can predict patient survival and increase our understanding of the biological behaviour of these tumours.

This study was supported by grants from the Special Trustees for the Former United Sheffield Hospitals and the Yorkshire Cancer Research Campaign.

The authors thank Mrs. M. E. Hudson for her secretarial assistance.

\section{References}

${ }^{1}$ Egan KM, Seddon JM, Glynn RJ, Gragoudas ES, Albert DM: Epidermiological aspects of uveal melanoma. Surv Ophthalmol 1988; 32: 239-51.

2 Paul EV, Parnell L, Fraker M: Prognosis of malignant melanoma of the choroid and ciliary body. Int Ophthal Clin 1962; 2: 387-402.

${ }^{3}$ Augsburger JJ, Gonder JR, Amsel J, Shields JA, Donoso LA: Growth rates and doubling times of posterior uveal melanomas. Ophthalmology 1984; 91: 1709-13.

${ }^{4}$ Friberg TR, Fineberg E, McQuaig S, Augusta G: 
Extremely rapid growth of a primary choroidal melanoma. Arch Ophthalmol 1983; 101: 1375-7.

${ }^{5}$ Friedlander ML, Hedley DW, Taylor IW: Clinical and biological significance of aneuploidy in human tumours. J Clin Pathol 1984; 37: 961-74.

${ }^{6}$ Meecham WJ and Char DN: DNA content abnormalities and prognosis in uveal melanoma. Arch Ophthalmol 1986; 104: 1626-9.

${ }^{7}$ Shapiro BE, Felberg NT, Donoso LA, Augsburger JJ, Shields JA, Gamel J: Flow cytometry of uveal melanomas. Cancer Biochem Biophys 1986; 8: 235-8.

${ }^{8}$ Hedley DW, Friedlander ML, Taylor IW, Rugg CA, Musgrove EA: Method for analysis of cellular DNA content of paraffin-embedded pathological material using flow cytometry. J Histochem Cytochem 1983 31: 1333-5.

${ }^{9}$ Lawry J, Rogers K, Percival RC, Day C, Potter CW, Underwood JCE: Flow cytometric DNA analysis of breast carcinomas: a comparative study of fresh, frozen and fixed embedded breast. Surg Res Comm 1987; 2: 27-37.

${ }^{10}$ Spencer. Ophthalmic Pathology: An atlas and textbook. Vol 3. Philadelphia. WB Saunders and Co. 1986; 2092.

${ }^{11}$ Shields JA: The management of posterior uveal melanomas in diagnosis and management of intraocular tumours. St Louis. CV Mosby 1983; 210-54.

${ }^{12}$ Engleholm SA, Spang-Thomsen M, Brunner N, Nohr I, Vindelov LL: Disaggregation of human solid tumours by combined mechanical and enzymatic methods. Br J Cancer 1985; 51: 93-8.
${ }^{13}$ Taylor IW, Milthorpe BK: An evaluation of DNA Fluorochromes, staining techniques and analysis for flow cytometry. J Histochem Cytochem 1980; 28: $1224-32$.

${ }^{14}$ Crissman HA and Tobey RA: Cell cycle analysis in 20 minutes. Science 1974; 184: 1297-8.

${ }^{15}$ Dean PN: A simplified method of DNA distribution analysis. Cell Tissue Kinet 1980; 13: 299-308.

${ }^{16}$ Hiddemann W, Schumann J, Andreef M, Barlogie B, Herman CJ, Leif RC, Mayall BH, Murphy RF, Sandberg AA: Convention on nomenclature for DNA cytometry. Cancer Genet Cytogenet 1984; 13: $181-3$.

${ }^{17}$ Barlogie B, Drewinko B, Schumann J, Gohde W, Dosik G, Latreilla J, Johnston DA, Freireigh EJ: Cellular DNA content as a marker of neoplasia in man. Am J Med 1980; 69: 195-203.

${ }^{18}$ Hansson J, Tribukait B, Lewensohn R, Ringborg U: Flow cytofluorometric DNA analyses of metastases of human malignant melanomas. Analytical and quantitative cytology. 1982; 25: 99-104.

${ }^{19}$ Sondergaard K, Larsen JK, Moller U, Christensen IJ, Jensen KH: DNA ploidy-characteristics of human malignant melanoma analysed by flow cytometry and compared with histology and clinical cause. Virchows Arch (Cell Pathol) 1983; 42: 31-8.

${ }^{20}$ Lang JR, Davidorf FM, Baba W: The prognostic significance of lymphocytic infiltrate in malignant melanoma of the chorioid. Cancer 1977; 40: 238894.

${ }^{21}$ Char D, Heibron RC, Juster RP, Stone RD. Choroidal melanoma growth patterns. Br J Ophthalmol 1983; 67: 575-78. 